\title{
Study of the Correlation of Diagnostic Efficacy of Modified Reids Colposcopic Index with Colposcopic Results
}

\author{
Authors \\ Zakia Rahman', Garima Yadav² \\ ${ }^{1,2}$ Department of Obstetrics and Gynaecology, Gajara Raja Medical College, Gwalior, \\ Madhya Pradesh, India \\ *Corresponding Author \\ Garima Yadav
}

\begin{abstract}
Purpose: This study is planned to correlate the diagnostic efficacy of Modified Reids Colposcopic index with colposcopic results

Materials \& Methods: This was a prospective in which colposcopy was carried out using Modified Reids colposcopic index (RCI) scoring system in the Department of Obstetrics and Gynaecology in 500 patients from October 2017 to April 2019.

Results: The sensitivity, specificity, positive predictive value and negative predictive value Modified RCI for Low grade lesion (LGL) was 92.8\%, 69.80\%, 66.2\% and $87.5 \%$ respectively. The sensitivity, specificity, positive predictive value and negative predictive value of Modified RCI for High grade lesion $(H G L)$ was $89.5 \%, 81.5 \%, 69.4 \%$ and $85.7 \%$ respectively.

Conclusion: Modified Reids Colposcopic Index system is consistent, has a simple structure, the only drawback being possibility of over interpretation of low grade lesions which regresses in due course of time with treatment/ observational follow up.

Keywords: Modified Reids Colposcopic Index, colposcopy, biopsy, efficacy.
\end{abstract}

\section{Introduction}

Unhealthy cervix is a very common finding in our country due to poor genital hygiene, malnutrition and multiparity. ${ }^{\left[{ }_{1}\right]}$ The naked eye evaluation of unhealthy cervix is deceptive sometimes and it so happens that intra-epithelial lesions are considered as simple cases of erosion due to inflammation.

Cancer uterine cervix is a serious health problem in India. in India, 122,844 women are diagnosed with cervical cancer and 67,477 died from the disease every year. ${ }^{[2]}$ The incidence of cervical cancer has decreased by more than $50 \%$ in the past 30 years, largely due to the increasing use of cervical cancer screening with cervical cytology. ${ }^{[3]}$ Screening aims to detect the disease at the premalignant stage when it is amenable to simple treatment and cure

Although worldwide cervical cancer rates have decreased dramatically with the increase in screening efforts, incidence and prevalence in developing countries remains high due ignorance 
and unawareness about screening programs in women in the developing countries. Invasive cancer of cervix has been considered a preventable cancer because it has a long pre-invasive state, cervical cytology screening programs are available and the treatment of pre-invasive lesions is effective. ${ }^{[4]}$ Pap smear has become routine method of cervical cancer screening. Its clinical utilization is rapidly expanding due to the simplicity of the technique, cost-effectiveness and less time taken to obtain the diagnosis. ${ }^{[5]}$

Cytology has got certain limitations like low sensitivity of $51 \%$ and a false negative rate of $49 \%$. Colposcopic directed biopsy of suspicious areas provides the final diagnosis in most situations and is taken as the gold standard in diagnosis of neoplastic lesions. This study is planned to correlate the diagnostic efficacy of Modified Reids Colposcopic index with colposcopic results.

\section{Method}

Source of Data: After aprroval of Institutional Ethical Committee, colposcopy was carried out using Modified Reids colposcopic index (RCI) scoring system in the Department of Obstetrics and Gynaecology in 500 patients who fulfilled the criteria of selection and gave consent to participate in the study. Patients were recruited during a period of 18 months (from October 2017 to April 2019)

Study Design: Prospective study

\section{Inclusion Criteria}

1) Recurrent episodes of white discharge per vagina

2) Intermenstrual bleeding, post-coital bleeding or post menopausal bleeding

3) Suspicious looking cervix (leukoplakia, cervical ectopy etc.)

\section{Exclusion Criteria}

1) Pregnant women

2) Clinically visible growth on cervix

3) Unmarried

\section{Procedure}

Written and informed consent were obtained from all the participants after brief explanation of the procedure. Menstrual and obstetric history was taken in relation to the presenting complaints. History of any previous surgery on cervix was noted. The patient was placed in dorsal position, the labia separated and the Cusco's self retaining speculum gently inserted without the use of lubricant or jelly. The cervix was exposed and visualized for any gross pathological features under adequate light and findings were recorded.

After preliminary inspection of the cervix, a Pap smear was taken using Ayre's spatula. The squamocolumnar junction was scraped with the Ayre's spatula by rotating full 360 degree. The scrapings were evenly spread on a glass slide and immediately fixed by dipping in the jar containing equal parts of 95\% ethyl alcohol and ether and transported to the pathological laboratory. Smears were analyzed by senior pathologist. Revised Bethesda System was used for describing Pap smear results.

Colposcopy was done in 240 women. Indication of colposcopy was, women with

- Abnormal Pap smear, with no gross lesion on the cervix of vagina.

- Women with postcoital bleeding.

- Naked eye examination reveals an unhealthy cervix suspicious of malignancy, especially with significant aceto whitening after acetic acid wash.

- Evaluation of women with a positive screening high- risk HPV DNA test.

- FUC of LEEP 
The modified Reid Colposcopic Index (RCI)

\begin{tabular}{|c|c|c|c|}
\hline Colposcopic signs & Zero point & One point & Two points \\
\hline Colour & $\begin{array}{l}\text { Low-intensity acetowhitening (not completely } \\
\text { opaque); indistinct acetowhitening; transparent } \\
\text { or translucent acetowhitening. } \\
\text { Acetowhitening beyond the margin of the } \\
\text { transformation zone Pure snow-white colour } \\
\text { with intense surface shine (rare) }\end{array}$ & $\begin{array}{l}\text { Intermediate shade - } \\
\text { grey/white colour and } \\
\text { shiny surface (most } \\
\text { lesions should be } \\
\text { scored in this } \\
\text { category) }\end{array}$ & $\begin{array}{l}\text { Dull, opaque, oyster white; } \\
\text { grey }\end{array}$ \\
\hline $\begin{array}{l}\text { Lesion margin and } \\
\text { surface configuration }\end{array}$ & $\begin{array}{l}\text { Microcondylomatous or micropapillary contour } \\
\text { Flat lesions with indistinct margins } \\
\text { Feathered or finely scalloped margins } \\
\text { Angular, jagged lesions } \\
\text { Satellite lesions beyond the margin of the } \\
\text { transformation zone }\end{array}$ & $\begin{array}{l}\text { Regular-shaped, } \\
\text { symmetrical lesions } \\
\text { with smooth, straight } \\
\text { outlines }\end{array}$ & $\begin{array}{l}\text { Rolled, peeling edges } \\
\text { Internal demarcations } \\
\text { between areas of differing } \\
\text { colposcopic appearance-a } \\
\text { central area of high-grade } \\
\text { change and peripheral area } \\
\text { of low-grade change }\end{array}$ \\
\hline Vessels & $\begin{array}{l}\text { Fine/uniform-calibre vessels- closely and } \\
\text { uniformly placed } \\
\text { Poorly formed patterns of fine punctation } \\
\text { and/or mosaic } \\
\text { Vessels beyond the margin of the } \\
\text { transformation zone } \\
\text { Fine vessels within microcondylomatous or } \\
\text { micropapillary lesions }\end{array}$ & Absent vessels & $\begin{array}{l}\text { Well defined coarse } \\
\text { punctation or mosaic, } \\
\text { sharply demarcated }- \text { and } \\
\text { randomly and widely } \\
\text { placed }\end{array}$ \\
\hline Iodine staining & $\begin{array}{l}\text { Positive iodine uptake giving mahogany brown } \\
\text { color } \\
\text { Negative uptake of insignificant lesion, i.e., } \\
\text { yellow staining by a lesion scoring } \\
\text { three points or less on the first three criteria } \\
\text { Areas beyond the margin of the transformation } \\
\text { zone, conspicuous on colposcopy, evident as } \\
\text { iodine-negative areas (such areas are frequently } \\
\text { due to parakeratosis) }\end{array}$ & $\begin{array}{l}\text { Partial iodine uptake } \\
\text { - variegated, speckled } \\
\text { appearance }\end{array}$ & $\begin{array}{l}\text { Negative iodine uptake of } \\
\text { significant lesion, i.e., } \\
\text { yellow staining by a lesion } \\
\text { already scoring four points } \\
\text { or more on the first three } \\
\text { criteria }\end{array}$ \\
\hline
\end{tabular}

Findings were recorded and colposcopy diagnosis was made based on Modified Reid Colposcopic Index (RCI). Biopsy was taken if Modified RCI was > 3. Cervical biopsy was taken for 128 patients.

\section{Results}

Maximum number of cases were found to be in the age group 25-34 years (35\%). The mean age was 38 \pm 6.7 years. In $73 \%$ cases, the age of first intercourse is $<20$ years

The commonest symptom with which patient presented in the clinic was recurrent white discharge per vagina $(80 \%)$ followed by menstrual irregularities in 168 (33.6) of cases. Table 2 shows that the most common indication of colposcopy was unhealthy looking cervix $(64.2 \%)$ followed by abnormal cytology.
Table 2: Distribution of patients according to indications for colposcopy

\begin{tabular}{|l|c|c|}
\hline Indication for colposcopy & $\begin{array}{c}\text { No. } \\
(\mathbf{n = 2 4 0})\end{array}$ & $\mathbf{\%}$ \\
\hline Unhealthy looking cervix & 154 & 64.2 \\
\hline Abnormal cytology & 61 & 25.4 \\
\hline Post coital bleeding & 12 & 5.0 \\
\hline $\begin{array}{l}\text { VIA ( Visual Inspection with Acetic } \\
\text { acid ) Positive }\end{array}$ & 10 & 4.2 \\
\hline $\begin{array}{l}\text { FUC of LEEP (Loop Electrosurgical } \\
\text { Excision Procedure) }\end{array}$ & 3 & 1.2 \\
\hline Total & 240 & \\
\hline
\end{tabular}

Table 3: Distribution of cases according to Modified RCI in the present study

\begin{tabular}{|l|c|c|c|}
\hline Modified RCI & $\begin{array}{c}\text { Colposcopic } \\
\text { impression }\end{array}$ & $\begin{array}{c}\text { No. } \\
(\mathbf{n = 2 4 0})\end{array}$ & \% \\
\hline $0-2$ & Normal & 114 & 47.5 \\
\hline $3-4$ & $\begin{array}{c}\text { Low grade } \\
\text { lesion(LGL) }\end{array}$ & 77 & 32.1 \\
\hline $5-8$ & $\begin{array}{c}\text { High grade lesion } \\
\text { (HGL) }\end{array}$ & 49 & 20.4 \\
\hline
\end{tabular}

Table 3 shows that $114(47.5 \%)$ patients were reported to have colposcopically normal impression 
while $49(20.4 \%)$ patients were reported to have high grade lesion.

Table 4: Agreement between colposcopic impression according to Modified RCI and HPE report of cervical biopsy

\begin{tabular}{|l|c|c|c|}
\hline & \multicolumn{3}{|c|}{ HPE report $\downarrow$} \\
\hline $\begin{array}{l}\text { Colposcopic } \\
\begin{array}{l}\text { Impression } \\
\text { according to RCI }\end{array}\end{array}$ & $\begin{array}{c}\text { Chronic } \\
\text { Cervicitis/ } \\
\text { Benign(n=51) }\end{array}$ & $\begin{array}{c}\text { CIN I } \\
(\mathrm{n}=28)\end{array}$ & $\begin{array}{c}\text { CIN II+III } \\
(\mathrm{n}=49)\end{array}$ \\
\hline Normal $(\mathrm{n}=2)$ & 0 & 1 & 1 \\
\hline LGL(n=77) & 40 & 23 & 14 \\
\hline HGL(n=49) & 11 & 4 & 34 \\
\hline
\end{tabular}

Table 4 shows out of 28 cases who were reported as CIN I based on histopathology, 23 cases had similar colposcopic impression according to modified RCI while 4 cases were reported as HGL. Using kappa statistics $\quad(\kappa=0.705, \mathrm{p}<0.001)$, the colposcopic impression according to Modified RCI and HPE report showed good level of agreement.

Table 5: Diagnostic accuracy of Modified RCI based on histopathology report (gold standard)

\begin{tabular}{|l|c|c|}
\hline & $\begin{array}{c}\text { No. } \\
(\mathrm{n}=240)\end{array}$ & $\%$ \\
\hline True positive & 75 & 31.2 \\
\hline False positive & 51 & 21.2 \\
\hline True negative & 112 & 46.7 \\
\hline False negative & 2 & 0.83 \\
\hline
\end{tabular}

The sensitivity, specificity, positive predictive value and negative predictive value Modified RCI for Low grade lesion(LGL) was 92.8\%,69.80\%, 66.2\% and $87.5 \%$ respectively. The sensitivity, specificity, positive predictive value and negative predictive value of Modified RCI for High grade lesion(HGL ) was $89.5 \%, 81.5 \%, 69.4 \%$ and $85.7 \%$ respectively, shown in Table 6

Table 6: Validity parameters of Modified RCI score

\begin{tabular}{|l|c|c|c|}
\hline S.no & Validity parameters & LGL & HGL \\
\hline 1 & Sensitivity & $92.8 \%$ & $89.5 \%$ \\
\hline 2 & Specificity & $69.80 \%$ & $81.5 \% \%$ \\
\hline 3 & Positive predictive value & $66.2 \%$ & $69.4 \%$ \\
\hline 4 & Negative Predictive value & $87.5 \%$ & $85.7 \%$ \\
\hline 5 & Inherent validity/Accuracy & $74.5 \%$ & $75.3 \%$ \\
\hline
\end{tabular}

\section{Discussion}

The incidence of cervical cancer can be reduced by as much as $80 \%$ if the quality, coverage and followup of screening methods are of high standard. ${ }^{[6]}$

Frequently repeated cytology screening programs have led to a large decline in cervical cancer incidence and mortality in developed countries. Cytology based screening programs have achieved very limited success in developing countries like India due to lack of trained personnel, laboratory facilities, equipments, high cost of services and poor follow-up. It has become necessary to find out alternative screening procedure to cytology which has high sensitivity and specificity. ${ }^{[6]}$

In the present study, the maximum number of patients was in the age group of 25-34 years (35\%) and mean age was $38 \pm 6.7$ years. The predilection for this group for the squamous intraepithelial lesions has been postulated by Knoblich et al. ${ }^{[7]}$ Sedlis et al stated that the highest rate of dysplasia is found in 20-29 years age group. ${ }^{[8]}$

In our study, the commonest symptom was recurrent white discharge per vagina $(80 \%)$ similar to study done by Swaminathan et al discharges per vagina was the most common complain, yet post menopausal bleeding was the harbinger of malignancy. ${ }^{[9]}$

In our clinical scenario patients do not have good compliance so patients with unhealthy looking cervix on clinical examination were directly referred for colposcopy without waiting for cervical cytology report. In the present study unhealthy looking cervix on clinical examination $(64.4 \%)$ was the most common indication followed by abnormal cytology (25.0\%). directly referred for colposcopy without waiting for cervical cytology report. Kalyankar et al reported unhealthy looking cervix on clinical examination as the main indication for colposcopy referral while abnormal pap smear report was most common indication in the study by Strander et al. ${ }^{[10],[11]}$ This disparity could be explained by better cervical screening program and educational status of patient in developed countries contributing to regular follow up and improved compliance. 
The sensitivity, specificity, positive predictive value and negative predictive value Modified RCI in our study was comparable to that of Kushwah et al. ${ }^{[12]}$ Massad et al concluded a poor (0.20) association between colposcopic impression and histology report and the sensitivity and specificity of colposcopy was shown to be $89 \%$ and $52 \%$ respectively. ${ }^{[13]}$

\section{Conclusion}

Modern colposcopy is an intermediate link between cytology and histopathology. Colposcopy is a highly sensitive tool in the early diagnosis of dysplasia and invasive cancer. Colposcopic guided biopsy is a gold standard for confirmation of diagnosis of CIN.

We concluded that Modified Reids Colposcopic Index system is consistent, has a simple structure, the only drawback being possibility of over interpretation of low grade lesions which regresses in due course of time with treatment/ observational follow up.

There is high non compliance during follow up, due to maximum patients being from rural area immediate colposcopy with pap smear sampling can solve this problem of poor follow-up non compliances, especially in rural population. It is also recommended, that combined use of pap smear colposcopy and colposcopic guided biopsy can be the protocol to evaluate all suspicious lesions of cervix.

\section{Conflict of interest: None \\ Source of support: Nil \\ Ethical Permission: Obtained}

\section{References}

1. Arora R, Vijaya K, Habeebullah S, Asha O, Colposcopic evaluation of unhealthy cervix. J Obstet Gynecol Ind. 2000;50:102-3.

2. Kaarthigeyan K. Cervical cancer in India and HPV vaccination. Indian J Med Paediatr Oncol. 2012;33:7-12.
3. ACOG Practice Bulletin no. 109: Cervical cytology screening. Obstet Gynecol. 2009 Dec. 114(6):1409-20.

4. Jonathan S. Berek. Berek and Novak's Gynecology.13 ${ }^{\text {th }}$ Edn. Lippincott Williams and Wilkins, Philadelphia; 2002: 1199.

5. Das S.K., Nigam S., Batra A., Chandra M. An atlas of colposcopy, cytology and Histopathology of lower female genital tract. CBS Publishers and Distributors, New Delhi; 2008: 129.

6. Sankanarayanan R, Madhukar AB, Rajkumar R. Effective screening programs for cervical cancer in low and middle income developing countries. Bulletin of World Health Organization 2001;79:954962.

7. Knoblich R, Rawson A. A clinicopathological study of 56 cases showing atypical epithelial changes of the cervix uteri. Am J Obstet Gynecol. 1957; 73:120-6.

8. Sedlis A, Sall S, Tsukada Y, Park R, Mangan C, Shingleton $\mathrm{H}$, et al. Microinvasive carcinoma of the uterine cervix: aclinicalpathologic study. Am J Obstet Gynaecol. 1979;133:64-74.

9. Swaminathan, T, Lahoti C, Khanna V et al: Post menopausal squamous cell atypias: diagnostic challenge, Diagn Cytopathol. 1994;11:226-30.

10. Kalyankar VY, Kalyankar BV, Gandappa $\mathrm{SN}$, Kute S. Colposcopic evaluation of unhealthy cervix and it's correlation with Papanicolau smear in cervical screening. Int J Reprod Contracept Obstet Gynecol. 2017 Nov;6(11):4959-65.

11. Strander B, Ellström-Andersson A, Franzén S, Milsom I, Rådberg T. The performance of a new scoring system for colposcopy in detecting high-grade dysplasia in the uterine cervix. Acta Obstet Gynecol Scand. 2005; 84:1013-1017.

12. Kushwah S, Kushwah B. Correlation of Two Colposcopic Indices for Predicting 
Premalignant Lesions of Cervix. J Midlife Health. 2017;8:118-123

13. Massad LS, Collins C, Yvonne. Strength of correlation between colpsocopic impression and biopsy histology. Gynaecologic Oncology 2003;89:424-8. 